\title{
Synthesis, Characterization and Theoretical Studies of New Organotellurium Compounds Based on (4-(((1S,E)-1,7,7-trimethylbicyclo[2.2.1] heptan-2- ylidene)amino)phenyl)mercury(II) Chloride
}

\author{
Nuha Hussain Al-Saadawy \\ Department of Chemistry, College of Science, University of Thi-Qar, Thi-Qar, Iraq
}

\section{* Corresponding author: \\ email:nuh.hussain@sci.utq.ed.iq}

Received: May 27, 2021

Accepted: July 7, 2021

DOI: $10.22146 /$ ijc. 66143

\begin{abstract}
The current study aimed to prepare new organomercury and organotellurium compounds based on the condensation reaction of 1,7,7-trimethylbicyclo[2.2.1]heptan-2one (camphor) and p-aminophenyl mercuric(II) chloride. All the prepared compounds were characterized using different methods such as infrared spectroscopy, nuclear magnetic resonance, and CHN analysis. The analysis results concurred with the suggested chemical structures of the prepared compounds. Density functional theory has been applied with the basis set of 3-21G to investigate the molecular structure of the prepared organotellurium compounds. Geometrical structure, HOMO surfaces, LUMO surfaces, and energy gap have been produced throughout the geometry optimization. The molecular geometry and contours for organotellurium compounds have been investigated throughout the geometrical optimization. Also, the donor and acceptor have been studied by comparing the HOMO energies of the prepared organotellurium compounds. Finally, the electronegativity, electrophilicity, ionization potential, electron affinity, and lower case of organotellurium compounds have been calculated and discussed.
\end{abstract}

Keywords: organotellurium; HOMO and LUMO energies; camphor and Density functional theory

\section{- INTRODUCTION}

Although the first organotellurium compound was prepared in 1840, this field of organic chemistry had not been systematically studied until the middle of the present century [1]. The first serious attempt to systematize organotellurium chemistry was undertaken by Rheinboldt, a German chemist who introduced chemistry in Brazil in 1934 [1]. In the last ten years, considerable development of organic tellurium chemistry has been observed, and several review articles and books on the subject have been published, focusing on the general reactions used to prepare the organotellurium compounds and the useful synthetic transformations promoted or suffered by them [2-5]. Recently, emphasis has been given to the recent contributions of the related laboratory where they explored old reactions trying to establish their generality or make transformations into the organotellurium compounds, which can lead to applicable synthetic methodologies [4,6-11]. The quantum mechanical wave function contains all the information about the studied system. Then, the allowed energy states of the system can be determined. Some approximations must involve a solved problem, albeit tricky [12-13]. Density functional theory (DFT) is referred by computational codes in the Gaussian 09 program and can be used in applications to investigate the structural, electronic, and some physical properties of the molecules and materials, such as the binding energies of the molecules in chemistry, physics, and other areas [14-17]. Density functional theory deals with Gaussian orbitals, in which Gaussian function changes exponentially with the square value of the position [18-19]. One of the most popular 12 basis sets in density functional theory is the hybrid functional B3LYP [20]. The purpose of the present study is to prepare organomercury and organotellurium compounds derived from 1,7,7-trimethylbicyclo[2.2.1]heptan-2-one (camphor) and $p$-aminophenyl mercuric(II) chloride and their derivatives by a condensation reaction. 


\section{- EXPERIMENTAL SECTION}

\section{Materials}

The chemicals used included Camphor, ethanol absolute, glacial acetic acid, mercuric acetate, bromine, chloroform, dioxin, sodium metal, potassium hydroxide, toluene, hydrazine hydrate, methanol, petroleum ether $\left(60-80{ }^{\circ} \mathrm{C}\right)$ (Sigma-Aldrich), Aniline (Avantor), Lithium chloride (VWR), Tellurium powder (Strem chemicals Inc.), Hydrochloric acid (HGB), and Molecular sieves (ACS). All were used without further purification.

\section{Instrumentation}

${ }^{1} \mathrm{H}$-NMR spectra were recorded on Bruker $500 \mathrm{MHz}$ spectrometers with TMS as an inner reference utilizing soluble DMSO- $\mathrm{d}_{6}$. Elemental analysis for carbon, hydrogen, and nitrogen was performed using a Euro vector EA 3000A Elemental Analysis (Italy). Infrared spectra were recorded with $\mathrm{KBr}$ circles utilizing an FT-IR spectrophotometer Shimadzu model $8400 \mathrm{~S}$ in $4000-250 \mathrm{~cm}^{-1}$.

\section{Procedure}

\section{(E)-(4-((1,7,7-trimethylbicyclo[2.2.1]heptan-2-ylidene) amino)phenyl)mercury(II) chloride (A)}

1,7,7-Trimethylbicyclo[2.2.1]heptan-2-one $(0.04 \mathrm{~mol}$, $6.08 \mathrm{~g}$ )was dissolved in $25 \mathrm{~mL}$ of hot ethanol. Then, 3 drops of glacial acetic acid were added and the mixture was stirred for $15 \mathrm{~min}$ in a water bath $\left(70^{\circ} \mathrm{C}\right)$. The formed solution of $0.04 \mathrm{~mol}$ (13.13 g) (4-aminophenyl) mercury(II) chloride [21-22] was then added to $25 \mathrm{~mL}$ of ethanol and the mixture was stirred for $16 \mathrm{~h}$ in a water bath $\left(70{ }^{\circ} \mathrm{C}\right)$, then filtrated and cooled at a room temperature. White crystals were formed with a yield of $85 \%$ and a melting point of $179-181^{\circ} \mathrm{C}$. $\mathrm{CHN}$ : theoretical \%: C, 41.56; H, 4.36; N, 3.03; practical \%: C, 41.40; H, 4.95; N, 3.45; FT-IR using KBr: $v(\mathrm{C}-\mathrm{H})$ Aliphatic $=2337 \mathrm{~cm}^{-1}, v(\mathrm{C}-\mathrm{H})$ Aromatic $=3164 \mathrm{~cm}^{-1}, v(\mathrm{C}=\mathrm{N})$ Aliphatic $=1612 \mathrm{~cm}^{-1}, \mathrm{v}$ $(\mathrm{C}-\mathrm{N})$ Aromatic $=1249 \mathrm{~cm}^{-1}, v(\mathrm{C}=\mathrm{C})$ Aromatic $=1490$ $\mathrm{cm}^{-1}$; ${ }^{1} \mathrm{H}-\mathrm{NMR}$ (500 MHz, DMSO- $\left.d_{6}\right) \delta_{10} \mathrm{CH}_{3},{ }_{11} \mathrm{CH}_{3}(6 \mathrm{H}$, s, 1.90); ${ }_{1} \mathrm{CH}_{3}$ (3H, s, 2.33); ${ }_{7} \mathrm{CH}_{2},{ }_{8} \mathrm{CH}_{2}(4 \mathrm{H}, \mathrm{m}, 2.75-2.79)$; ${ }_{5} \mathrm{CH}_{2}(2 \mathrm{H}, \mathrm{t}, 4.85) ;{ }_{6} \mathrm{CH}(1 \mathrm{H}, \mathrm{s}, 5.77)$; $\mathrm{Ar}-\mathrm{H}(4 \mathrm{H}, \mathrm{m}, 8.23-$ 9.20). As shown in Scheme 1, Table 1 and 2, Fig. 1.

\section{(E)-1,7,7-trimethyl-N-(4-(tribromo-I4-tellaneyl) phenyl)} bicyclo[2.2.1] heptan-2-imine (B)

A solution of (E)-(4-((1,7,7-trimethylbicyclo[2.2.1] heptan-2-ylidene)amino)phenyl) mercury(II) chloride (0.008 mol., $3.69 \mathrm{~g})$ and tellurium tetrabromide $(0.008 \mathrm{~mol} ., 3.57 \mathrm{~g})$ in dry dioxane $60 \mathrm{~mL}$ was refluxed for $14 \mathrm{~h}$. The solution was filtered while hot. After cooling to room temperature [23], the formed brown precipitate was collected by filtration. Recrystallization by using glacial acetic acid to give reddish-brown crystals, yield $65 \%$, m.p. $165-166^{\circ} \mathrm{C}, \mathrm{CHN}$ : theoretical \%: C, 32.37; H, 3.40; N, 2.36; practical \%: C, 31.99; H, 3.23; N, 2.76; FTIR using KBr: $v(\mathrm{C}-\mathrm{H})$ Aliphatic $=2300 \mathrm{~cm}^{-1}, v(\mathrm{C}-\mathrm{H})$ Aromatic $=3170 \mathrm{~cm}^{-1}, v(\mathrm{C}=\mathrm{N})$ Aliphatic $=1629 \mathrm{~cm}^{-1}$, $v(\mathrm{C}-\mathrm{N})$ Aromatic $=1224 \mathrm{~cm}^{-1}, v(\mathrm{C}=\mathrm{C})$ Aromatic $=$ $1402 \mathrm{~cm}^{-1}$; ${ }^{1} \mathrm{H}-\mathrm{NMR}\left(500 \mathrm{MHz}, \mathrm{DMSO}-d_{6}\right) \delta{ }_{10} \mathrm{CH}_{3}$, ${ }_{11} \mathrm{CH}_{3}(6 \mathrm{H}, \mathrm{s}, 1.91) ;{ }_{1} \mathrm{CH}_{3}(3 \mathrm{H}, \mathrm{s}, 1.35) ;{ }_{7} \mathrm{CH}_{2},{ }_{8} \mathrm{CH}_{2}(4 \mathrm{H}, \mathrm{s}$, 2.08); ${ }_{5} \mathrm{CH}_{2}$ (2H, s, 5.95); 6 CH (1H, s, 2.35); $\mathrm{Ar}-\mathrm{H}$ (4H, m, 7.83-9.12). As shown in Scheme 1, Table 1 and 2, Fig. 2.

(E)-4-(dibromo(4-((1,7,7-trimethylbicyclo[2.2.1] heptan -2-ylidene)amino)phenyl)-14-tellaneyl)aniline (C)

A solution of (E)-1,7,7-trimethyl-N-(4-(tribromo14-tellaneyl)phenyl)bicyclo[2.2.1] heptan-2-imine (0.0035 mol., $2.07 \mathrm{~g}$ ) and (4-aminophenyl)mercury(II) chloride $(0.0035$ mol., $1.14 \mathrm{~g})$ in $(25 \mathrm{~mL})$ of dry dioxane was refluxed for $4 \mathrm{~h}$. The hot mixture was then filtered, and the filtrate was cooled to room temperature, leading to the precipitation of white plates of 2:1 complexes of dioxane and mercuric bromochloride that were filtered off. The filtrate was poured into $100 \mathrm{~mL}$ of cold distilled water to form brown crystals [23], with a yield of 59\%, and a melting point of $143-145^{\circ} \mathrm{C}, \mathrm{CHN}$ : theoretical \%: C, 43.61; H, 4.33; N, 4.62; practical \%: C, 43.34; H, 4.13; $\mathrm{N}, 4.43$; FT-IR using KBr: $\mathrm{v}(\mathrm{C}-\mathrm{H})$ Aliphatic $=2925 \mathrm{~cm}^{-1}$, $v(\mathrm{C}-\mathrm{H})$ Aromatic $=3068 \mathrm{~cm}^{-1}, v(\mathrm{C}=\mathrm{N})$ Aliphatic $=$ $1627 \mathrm{~cm}^{-1}, v(\mathrm{C}-\mathrm{N})$ Aromatic $=1280 \mathrm{~cm}^{-1}, v(\mathrm{C}=\mathrm{C})$ Aromatic $=1460 \mathrm{~cm}^{-1} ;{ }^{1} \mathrm{H}-\mathrm{NMR}\left(500 \mathrm{MHz}, \mathrm{DMSO}-d_{6}\right)$ $\delta{ }_{1} \mathrm{CH}_{3,10} \mathrm{CH}_{3},{ }_{11} \mathrm{CH}_{3},{ }_{5} \mathrm{CH},{ }_{7} \mathrm{CH}_{2},{ }_{8} \mathrm{CH}_{2}(13 \mathrm{H}, \mathrm{m}, 1.80-$ 2.31); ${ }_{6} \mathrm{CH}$ (1H, s, 5.74); Ar-H (8H, m, 7.92-8.90); $\mathrm{NH}_{2}$ $(2 \mathrm{H}, \mathrm{s}, 4.19)$ as shown in Scheme 2., Table 1 and 2, Fig. 3. 


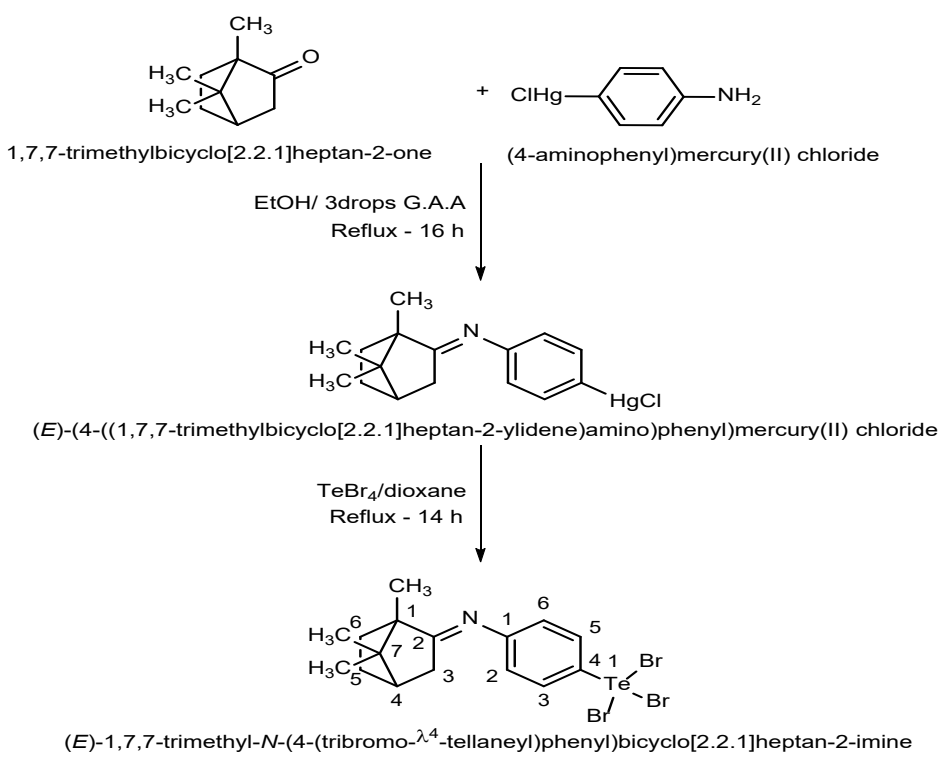

Scheme 1. Preparation of organomercury and organyl tellurium tribromide compounds

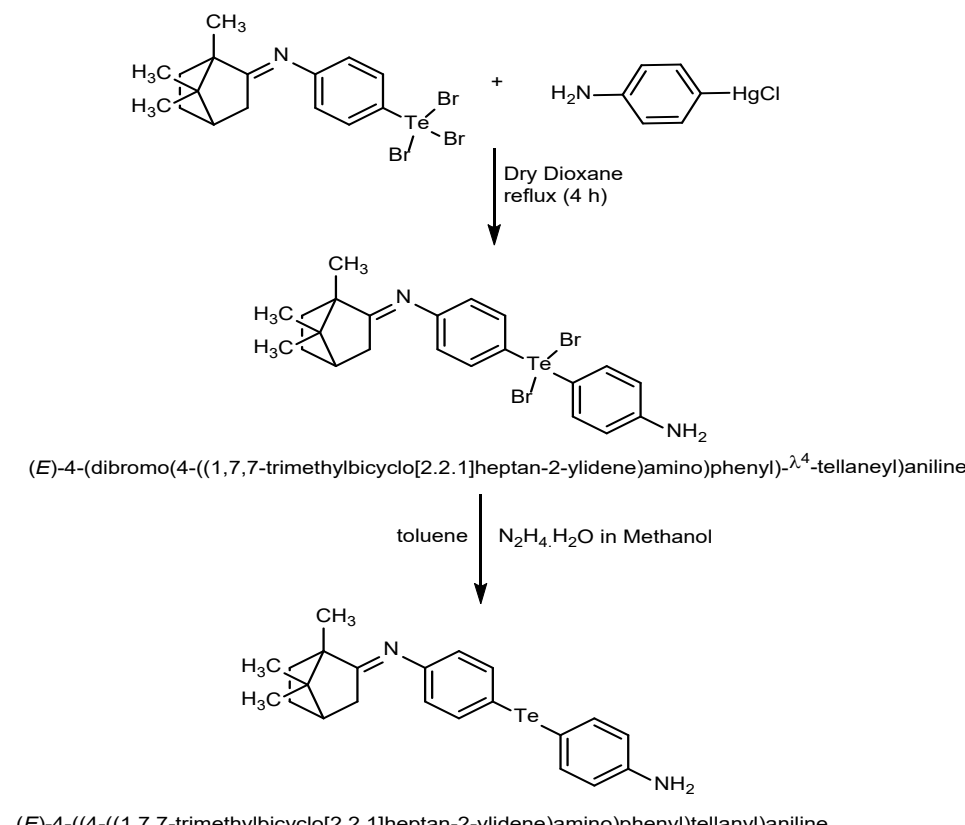

Scheme 2. Preparation of organyl tellurium dibromide and diorganyl telluride

\section{(E)-4-((4-((1,7,7-trimethylbicyclo[2.2.1]heptan-2-ylide ne)amino)phenyl)tellanyl)aniline (D)}

(E)-4-(dibromo(4-((1,7,7-trimethylbicyclo[2.2.1]hep tan-2-ylidene)amino)phenyl)-14-tellaneyl)aniline (0.0032 mol., $1.94 \mathrm{~g})$ was dissolved in toluene $(30 \mathrm{~mL})$. To the refluxing solution, hydrazine hydrate $(0.0032 \mathrm{~mol}, 0.16 \mathrm{~g})$ in methanol $(30 \mathrm{~mL})$ was added dropwise. The resulting solution was poured into cold water $(100 \mathrm{~mL})$ and the brown solid that had formed was recrystallized from petroleum ether $\left(60-80{ }^{\circ} \mathrm{C}\right)$ to give brown crystals [23], with a yield of $53 \%$, and a melting point of $81-82{ }^{\circ} \mathrm{C}$; CHN: theoretical \%: C, 59.24; $\mathrm{H}, 5.88 ; \mathrm{N}, 6.28$; practical \%: C, 59.10; H, 5.31; N, 6.44; FT-IR using KBr: $\mathrm{U}(\mathrm{C}-\mathrm{H})$ Aliphatic $=2854 \mathrm{~cm}^{-1}, v(\mathrm{C}-\mathrm{H})$ Aromatic $=3205 \mathrm{~cm}^{-1}$, $v(\mathrm{C}=\mathrm{N})$ Aliphatic $=1635 \mathrm{~cm}^{-1}, v(\mathrm{C}-\mathrm{N})$ Aromatic $=$ $1280 \mathrm{~cm}^{-1}, \cup(\mathrm{C}=\mathrm{C})$ Aromatic $=1415 \mathrm{~cm}^{-1} ;{ }^{1} \mathrm{H}-\mathrm{NMR}$ (500 MHz, DMSO- $\left.d_{6}\right) \delta_{10} \mathrm{CH}_{3},{ }_{11} \mathrm{CH}_{3}(6 \mathrm{H}, \mathrm{s}, 1.90) ;{ }_{1} \mathrm{CH}_{3}$ (3H, s, 2.06); ${ }_{7} \mathrm{CH}_{2},{ }_{8} \mathrm{CH}_{2}(4 \mathrm{H}, \mathrm{s}, 2.20) ;{ }_{5} \mathrm{CH}_{2}(2 \mathrm{H}, \mathrm{d}, 2.33)$; 
Table 1. ${ }^{1} \mathrm{H}-\mathrm{NMR}$ spectral data of selected compounds



${ }_{6} \mathrm{CH}(1 \mathrm{H}, \mathrm{t}, 5.77) ; \mathrm{Ar}-\mathrm{H}(8 \mathrm{H}, \mathrm{m}, 8.02-9.02) ; \mathrm{NH}_{2}(2 \mathrm{H}, \mathrm{s}$, 4.09) as shown in Scheme 2, Table 1 and 2, Fig. 4.

\section{- RESULTS AND DISCUSSION}

The present study involved the preparation of organomercury and organotellurium compounds derived from 1,7,7-trimethylbicyclo[2.2.1]heptan-2-one (camphor) by reacting 1,7,7-trimethylbicyclo[2.2.1] heptan-2-one and (4-aminophenyl)mercury(II) chloride in absolute ethanol and adding three drops of glacial acetic acid to obtain (E)-(4-((1,7,7-trimethyl bicyclo[2.2.1]heptan-2-ylidene) amino)phenyl)mercury(II) chloride. (E)-(4-((1,7,7trimethyl bicyclo[2.2.1]heptan-2-ylidene)amino)phenyl) mercury(II) chloride then reacted with tellurium tetrabromide to give tellurium tribromide derivatives, starting materials for the remaining compounds prepared in this research.

${ }^{1} \mathrm{H}$-NMR spectra $[24,25]$ of the compounds (A-D) 
Table 2. FT-IR spectral data of selected compounds

\begin{tabular}{cccccc}
\hline Compound & Aliphatic C-H & Aromatic C-H & Aliphatic C=N & Aromatic C-N & Aromatic C=C \\
\hline A & 2337 & 3164 & 1612 & 1249 & 1490 \\
B & 2300 & 3170 & 1629 & 1224 & 1402 \\
C & 2925 & 3068 & 1627 & 1280 & 1460 \\
D & 2854 & 3205 & 1635 & 1280 & 1415 \\
\hline
\end{tabular}

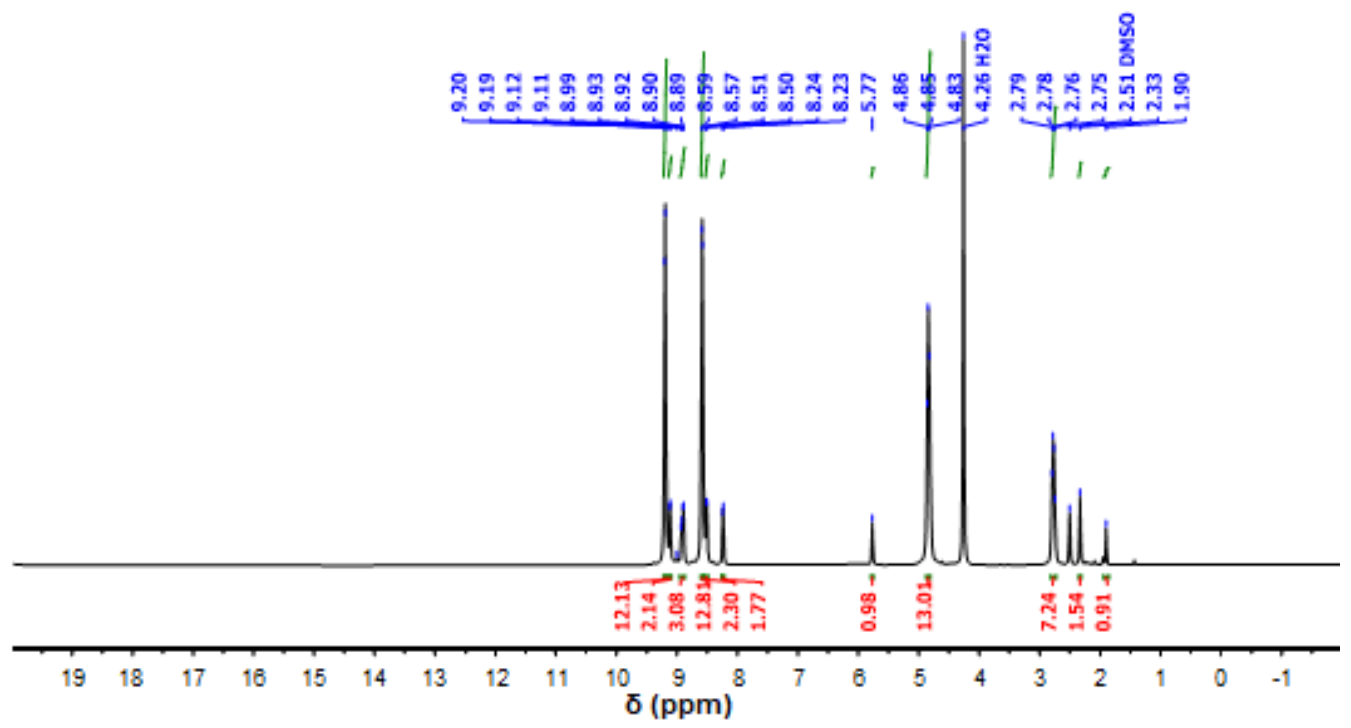

Fig 1. ${ }^{1} \mathrm{H}-\mathrm{NMR}$ spectrum of compound A

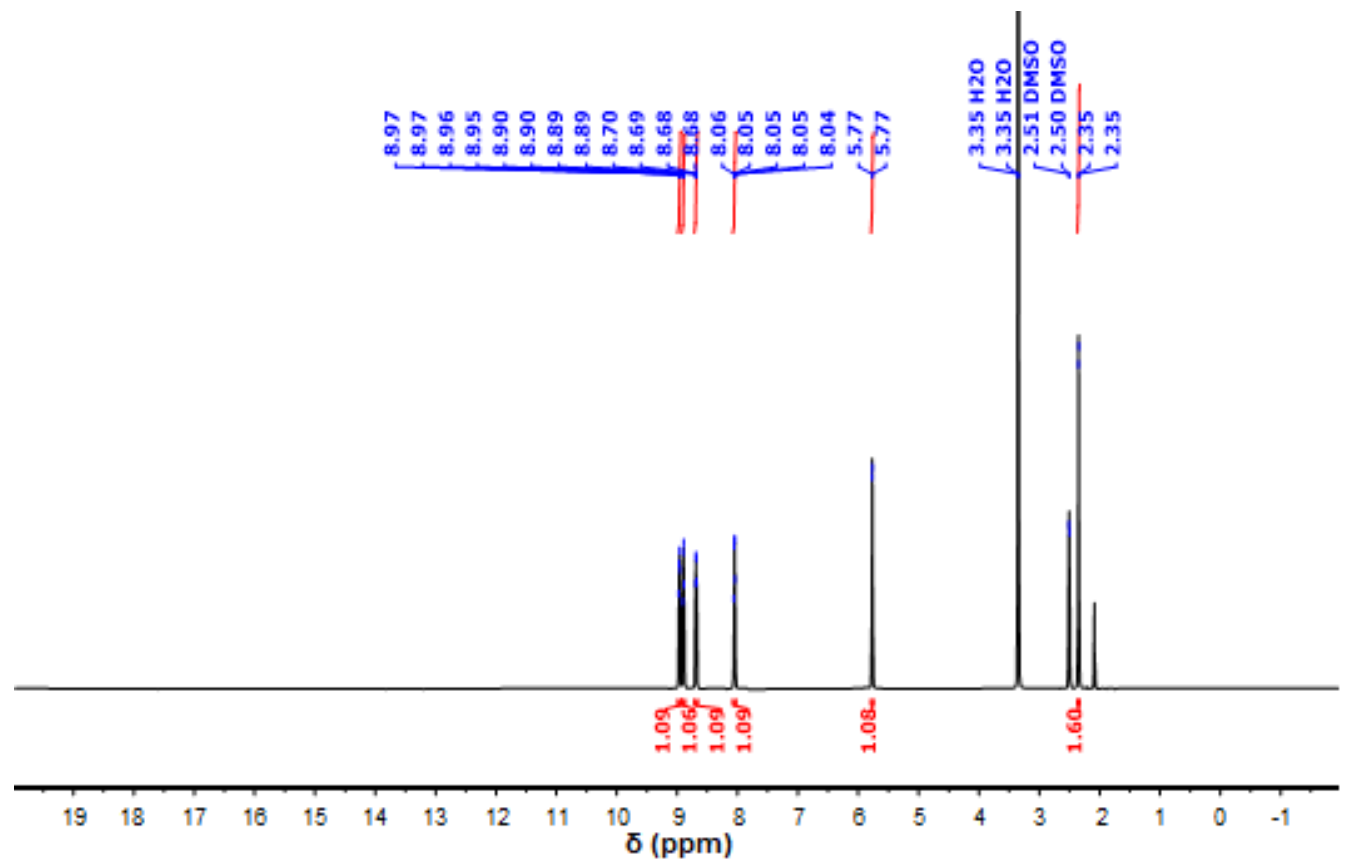

Fig 2. ${ }^{1} \mathrm{H}-\mathrm{NMR}$ spectrum of compound $\mathrm{B}$

showed all the expected peaks. All the spectra in deuterated DMSO are given in Table 1 and explained in Fig. (1-4).
All prepared compounds' IR spectra displayed common features in specific regions and characteristic bands in the fingerprint and other regions. The suggested 


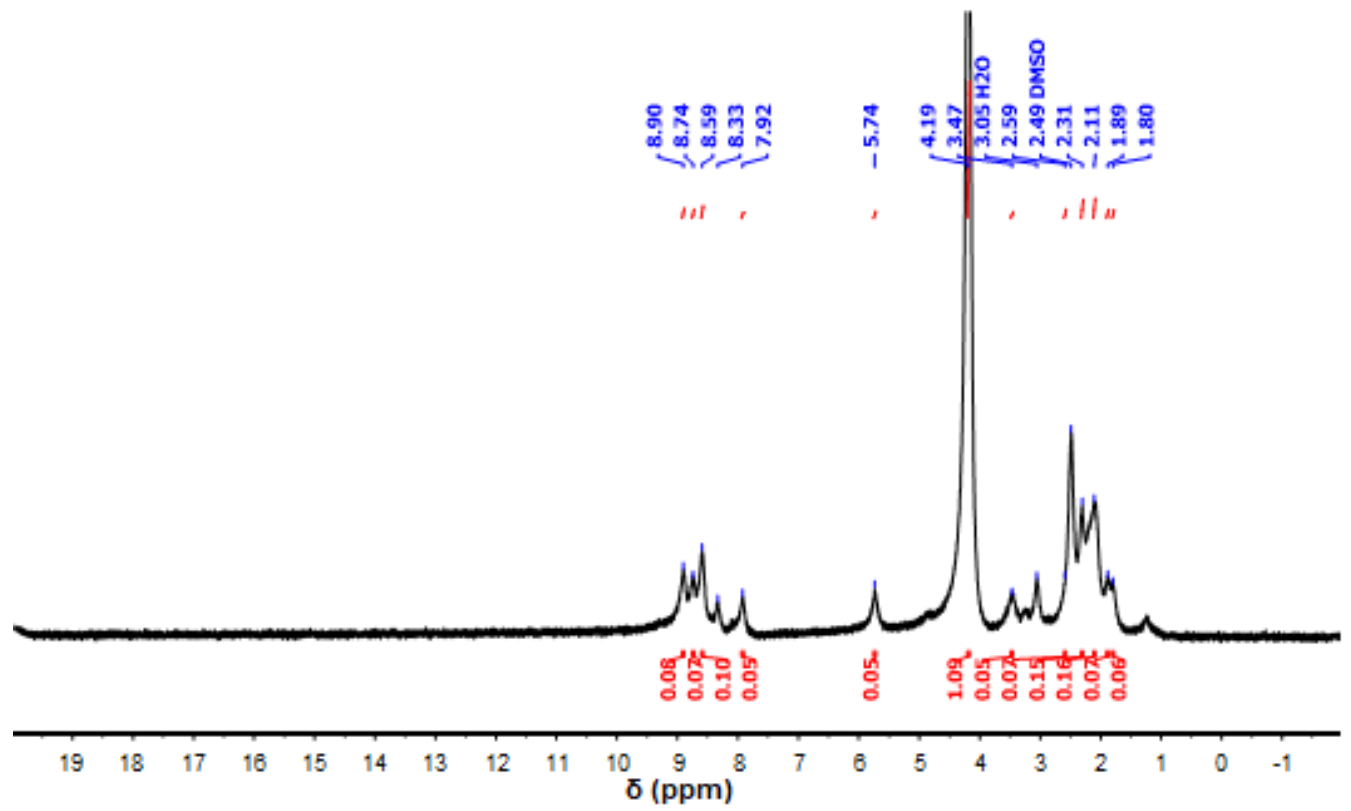

Fig 3. ${ }^{1} \mathrm{H}-\mathrm{NMR}$ spectrum of compound C



Fig 4. ${ }^{1} \mathrm{H}-\mathrm{NMR}$ spectrum of compound D

structure for the prepared compounds was confirmed using the IR spectra [24-25], as shown in Table 2. The aromatic C-H [24-25] appeared at $3068-3205 \mathrm{~cm}^{-1}$ for organomercury and organotellurium derivatives, whereas the aliphatic C-H was obtained at $2925-2300 \mathrm{~cm}^{-1}$ for the prepared compounds. On the other hand, the aliphatic $\mathrm{C}=\mathrm{N}$ group displayed an apparent band at $1612-1635 \mathrm{~cm}^{-1}$, while the band at the range of $1224-1280 \mathrm{~cm}^{-1}$ [24-25] was attributed to the aromatic $\mathrm{C}-\mathrm{N}$ for organomercury and organotellurium derivatives. The $\mathrm{C}=\mathrm{C}$ aromatic bond appeared at the range of $1402-1490 \mathrm{~cm}^{-1}$ [24-25], as shown in Table 2.

\section{Computational Study}

All the organotellurium compounds under study were labeled as shown in Fig. 5-16. The accuracy of the 




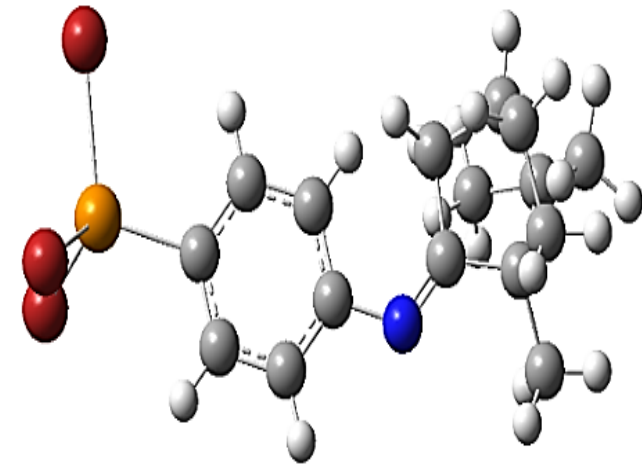

Fig 5. Molecular structure of compound B

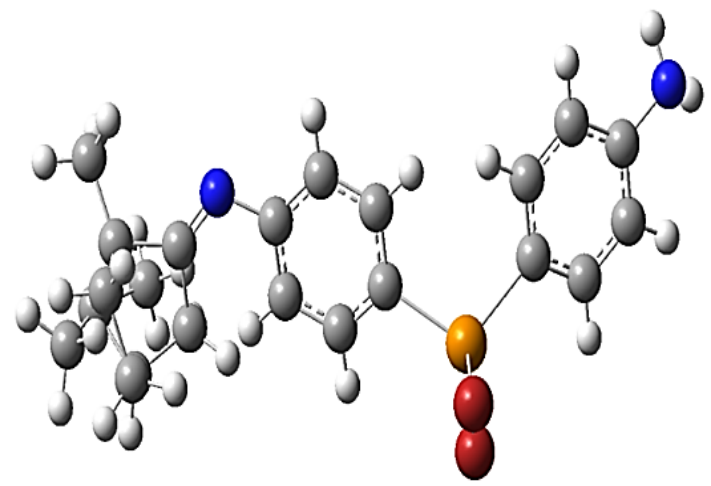

Fig 7. Molecular structure of compound C

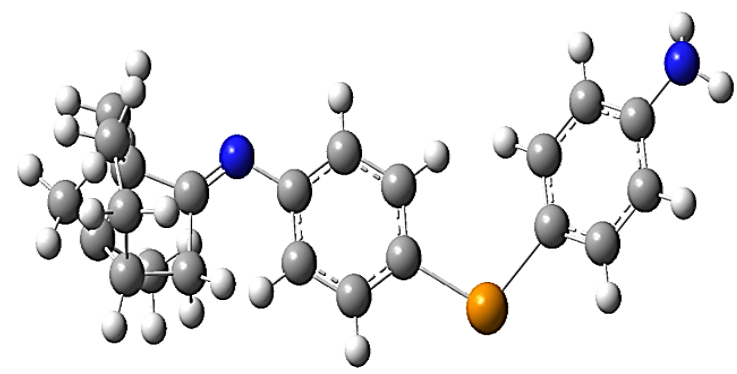

Fig 9. Molecular structure of compound D



Fig 11. Molecular orbital (HOMO) of compound B

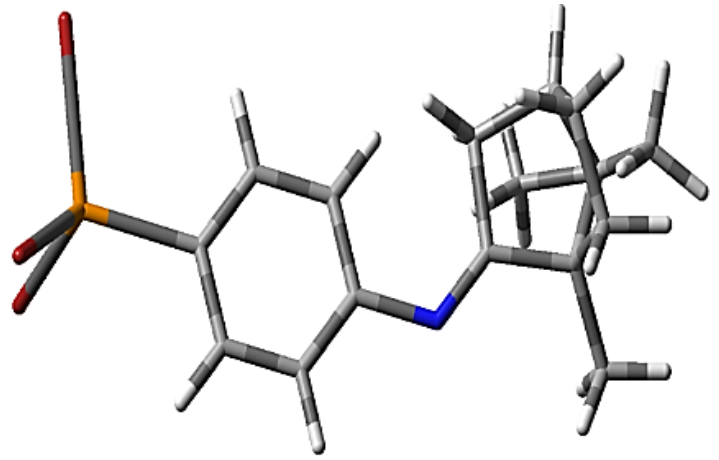

Fig 6. Sticks Molecular model of compound B

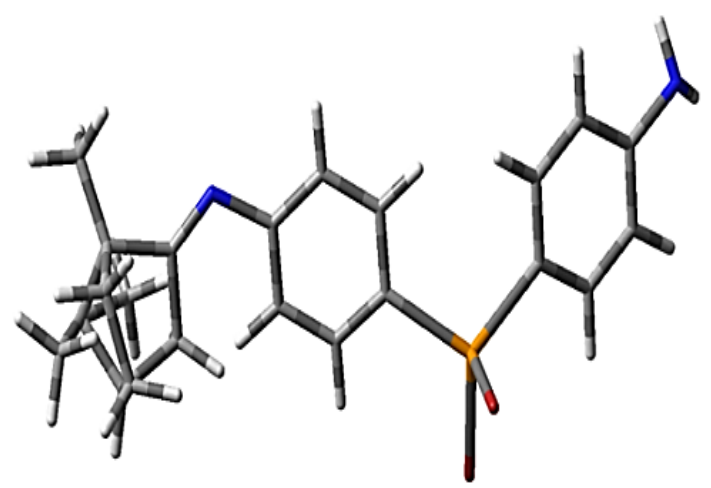

Fig 8. Sticks Molecular model of compound C



Fig 10. Sticks Molecular model of compound D

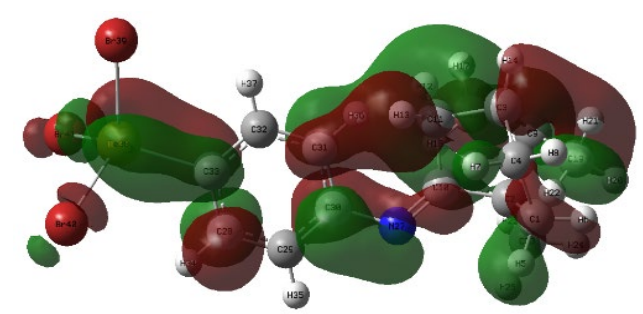

Fig 12. Molecular orbital (LUMO) of compound B 


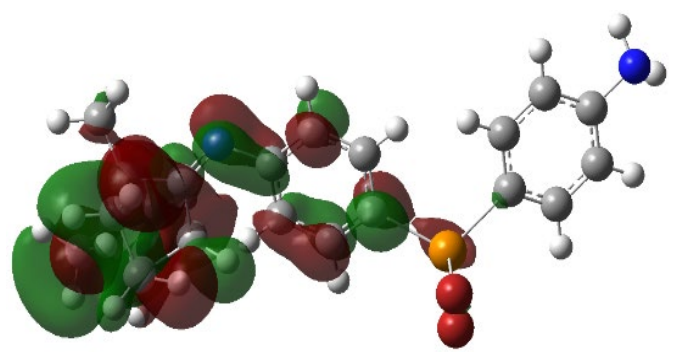

Fig 13. Molecular orbital (HOMO) of compound C

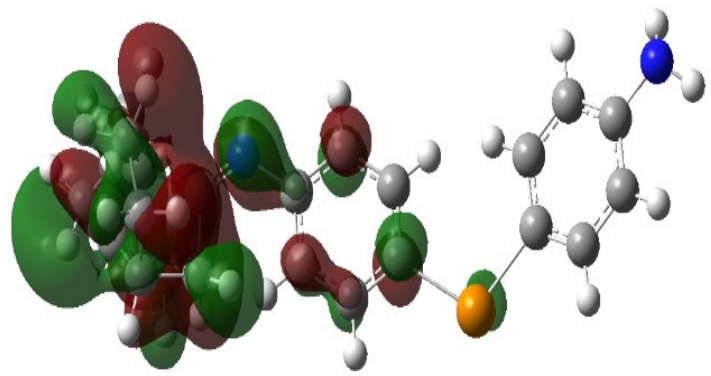

Fig 15. Molecular orbital (HOMO) of compound D

method was examined to describe the properties of the compound in the gas phase. The geometric structures and electronic properties were studied at all quantum calculations with the density functional theory (DFT) achieved at the hybrid functional B3LYP, which combines Becke's exchange and Lee, Yang, and Parr's correlation functional computational level [15,17]. This method described all atoms using the 3-21G basis set with Gaussian 09 program [19]. The reactivity and the stability of the compounds were evaluated using DFT-based descriptors that were calculated [26-27]:

$\mu=\left(\frac{\partial \mathrm{E}}{\partial \mathrm{N}}\right)_{\mathrm{V}(\overrightarrow{\mathrm{r}}), \mathrm{T}}$

$\eta=\frac{1}{2}\left(\frac{\partial^{2} \mathrm{E}}{\partial \mathrm{N}^{2}}\right)_{\mathrm{V}(\overrightarrow{\mathrm{r}}), \mathrm{T}}$

$S=\frac{1}{2 \eta}$

$\omega=\frac{\mu^{2}}{2 \eta}$

Where $\mu, \eta, S$, and $\omega$ are the chemical potential, chemical hardness, chemical softness, and electrophilicity, respectively, while $E, N$, and $V(\vec{r})$ are the total electron energy, number of electrons, and external potential, respectively. Two different methods were used to

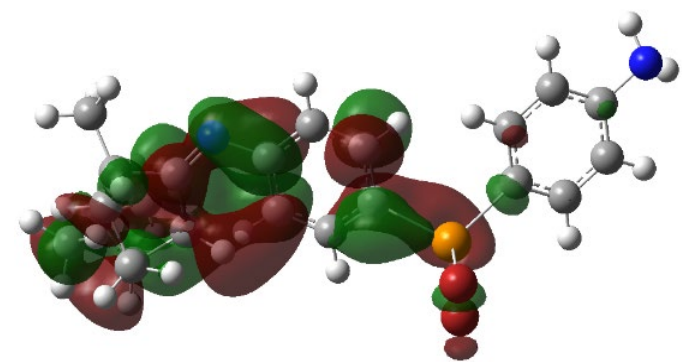

Fig 14. Molecular orbital (LUMO) of compound C

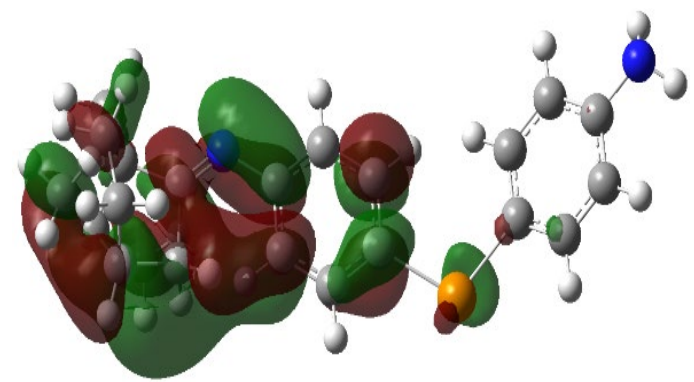

Fig 16. Molecular orbital (LUMO) of compound D

compute the above global quantities; the first is a finite difference approximation, based on the differences of total electronic energies when an electron is removed or added following the neutral molecule, and the second is Koopman's theorem, which is based on the differences between the HOMO and LUMO energies of the molecule [26-28]. By using a finite difference approximation, the global quantities can be given by [26-28]:

$\chi=\frac{(\mathrm{IP}+\mathrm{EA})}{2}$

$\eta=\frac{(\mathrm{IP}-\mathrm{EA})}{2}$

Then, using Koopman's theorem, the above equations are given by [28]:

$\chi=\frac{\left(\mathrm{E}_{\mathrm{HOMO}}+\mathrm{E}_{\mathrm{LUMO}}\right)}{2}$

$\eta=\frac{\left(\mathrm{E}_{\mathrm{HOMO}}-\mathrm{E}_{\mathrm{LUMO}}\right)}{2}$

\section{Electronic Properties}

The equilibrium geometries for all the study compounds were fully optimized at the DFT level of theory using a B3LYP functional along with the standard 3-21G basis set in the gaseous phase, see Fig. 5-16. 
HOMO (High Occupied Molecular Orbital) and LUMO (Low Unoccupied Molecular Orbital) energies are the electronic states, referring to certain places of the existence of the electrons with quantized energies, where the molecular orbitals are in linear combination to the atomic orbitals. The difference between HOMO gives energy bandgap ( $\left.\mathrm{E}_{\mathrm{g}}\right)$ as the relation [7]. The energy gap is a fundamental property in solids because it allows the prediction of the material, whether it is a conductor or insulator, or semiconductor. It stands for the energy difference between the lower virtual energy level and the higher full energy level [29], see Fig. (5-16) and Table 3.

$\mathrm{Eg}=\mathrm{E}_{\mathrm{LUMO}}-\mathrm{E}_{\mathrm{HOMO}}$

\section{Electronegativity and electrophilicity}

We can define electronegativity as the measure of the tendency of an atom to attract a shared pair of electrons (or electron density) towards itself. In contrast, relative rate constants measure electrophilicity for reactions of different electrophilic reagents towards a common substrate (usually involving an attack at a carbon atom). Electronegativity and electrophilicity can be calculated from the relations 10 and $11[15,20]$, see Table 4.

$\mathrm{x}=\frac{\mathrm{E}_{\mathrm{HOMO}}+\mathrm{E}_{\mathrm{LUMO}}}{2}$

$\omega=\frac{x^{2}}{2 \eta}$

\section{Ionization potential and electron affinity}

Ionization potential measures the binding force between the electron and the atom. It is equivalent to the required energy to remove one electron from a neutral atom in the gas state. Electron affinity can be defined as the energy released when an atom gains an electron. It is equivalent to the required energy that can remove an electron from a negative ion. According to Koopman's theory [15], as shown in Table 5.

$$
\begin{aligned}
& \text { I.P }=-\mathrm{E}_{\text {HOMO }} \\
& \text { E. } \mathrm{A}=-\mathrm{E}_{\text {LUMO }}
\end{aligned}
$$

\section{Hardness softness acid base (HSAB principle)}

This principle describes the behavior of molecules or atoms as the acids and bases in chemistry. First, it is necessary to show that the soft and hard bases represent
Table 3. Demonstrates electronic states of the organotellurium compounds

\begin{tabular}{cccc}
\hline Compound & HOMO $(\mathrm{eV})$ & LUMO $(\mathrm{eV})$ & $\mathrm{E}_{\mathrm{g}}(\mathrm{eV})$ \\
\hline B & -6.0017 & -5.6591 & 0.3426 \\
C & -5.1209 & -4.6333 & 0.4876 \\
D & -5.1312 & -4.8507 & 0.2805 \\
\hline
\end{tabular}

Table 4. Electronegativity and electrophilicity of the organotellurium compounds

\begin{tabular}{ccc}
\hline Compound & $\begin{array}{c}\text { Electronegativity }(\mathrm{eV}) \\
(\mathrm{X})\end{array}$ & $\begin{array}{c}\text { Electrophilicity }(\mathrm{eV}) \\
(\mathrm{w})\end{array}$ \\
\hline $\mathrm{B}$ & -5.8304 & -99.2223 \\
$\mathrm{C}$ & -7.7923 & -124.5281 \\
$\mathrm{D}$ & -4.9909 & -88.8341 \\
\hline
\end{tabular}

Table 5. Ionization potential and electron affinity of the organotellurium compounds

\begin{tabular}{ccc}
\hline Compound & $\begin{array}{c}\text { Ionization potential (eV) } \\
(\mathrm{I} . \mathrm{P})\end{array}$ & $\begin{array}{c}\text { Electron affinity }(\mathrm{eV}) \\
(\mathrm{E} . \mathrm{A})\end{array}$ \\
\hline B & 6.0017 & 5.6591 \\
C & 5.1209 & 4.6333 \\
D & 5.1312 & 4.8507 \\
\hline
\end{tabular}

donors, but soft and hard acids stand for acceptors. The following equations [28,30-32] can express hardness and softness:

$\eta=\frac{\text { I.P }- \text { E.A }}{2}$

$\sigma=\frac{1}{2 \eta}$

$\eta$ refers to chemical hardness, and $\sigma$ refers to chemical softness. As explained in Table 6.

\section{- CONCLUSION}

The present work describes the efficient routes to synthesis some novel unsymmetrical organotellurium compounds by a simple and convenient method. Compounds A, B, C, and D were obtained with a yield of $53-85 \%$. Findings from the present study on the CHN elemental analysis, FT-IR, and ${ }^{1} \mathrm{H}-\mathrm{NMR}$ concur with previous research, confirming the correctness of the proposed structures for all the prepared compounds. As for the theoretical study, it can be concluded that the density functional theory used in this study is a powerful method, and B3LYP functional is a suitable and efficient 
function for studying the electronic properties of these structures. The geometrical parameters of $6-31 \mathrm{G}(\mathrm{d}, \mathrm{p})$ concurred with the experimental data. Therefore, the density functional theory method has been used in this work to study geometry optimization and the electronic properties of naphthalene and di-amino naphthalene by using B3LYP functional.

The geometric structures and total energies donoracceptor system show that this structure is highly stable. Furthermore, the donor-acceptor system has large average polarizability compared with donor and acceptor and this system has higher reactivity than others. The results obtained in this work help us to select a type of bridge to interact with the donor and acceptor to calculate the physical properties of the donor-bridge-acceptor.

\section{- REFERENCES}

[1] Irgolic, K.J., 1974, The Organic Chemistry of Tellurium, Gordon and Breach Science Publishers.

[2] Gedridge, R.W., Higa, K.T., and Nissan, R.A., 2011, New organotellurium precursors for the pyrolytic and photolytic deposition of $\mathrm{Hg}_{1-\mathrm{x}} \mathrm{Cd}_{\mathrm{x}} \mathrm{Te}, M R S$ Online Proc. Libr., 131, 69-73.

[3] Torubaev, Y.V., Pavlova, A.V., and Pasynskii, A.A., 2012, Metal-metal bond cleavage in $\left[\mathrm{Cp}(\mathrm{CO})_{2} \mathrm{Fe}-\right.$ $\left.\mathrm{Fe}(\mathrm{CO})_{2} \mathrm{Cp}\right]$ under the action of organotellurium(IV) tribromides, Russ. J. Coord. Chem., 38 (3), 219-223.

[4] Al-Asadi, R.H., 2020, Synthesis and molecular structure study of new organotellurium and organomercury compounds based on 4bromonaphthalen-1-amine, Russ. J. Gen. Chem., 90 (9), 1744-1749.

[5] Wang, S., Yan, C., Zhao, W., Liu, X., Yuan, C.S., Zhang, H.L., and Shao, X., 2021, A tellura-BaeyerVilliger oxidation: One-step transformation of tellurophene into chiral tellurinate lactone, Chem. Sci., 12 (16), 5811-5817.

[6] Al-Fregi, A.A., and Adnan, M.A., 2016, Synthesis, characterization and analytical study of tellurated Schiff base of bis[2-(3-nitrobenzylideneamino)-5nitrophenyl]telluride and its complexation reactions with $\mathrm{Mn}(\mathrm{II}), \mathrm{Co}(\mathrm{II})$ and $\mathrm{Ni}(\mathrm{II})$ ions, Eur. J. Chem., 7 (2), 195-200.
[7] Al-Asadi, R.H., 2019, Synthesis, DFT calculation and biological activity of some organotellurium compounds containing azomethine group, Orbital: Electron. J. Chem., 11 (7), 402-410.

[8] Al-Asadi, R.H., Mohammed, M.K., and Dhaef, H.K., 2020, Mercuration and telluration of 2fluoro-5-nitroaniline: Synthesis, antibacterial, and computational study, Russ. J. Gen. Chem., 90 (4), 703-709.

[9] Al-Saadawy, N.H., and Abowd, M.I., 2019, Synthesis and identification of new organoselenium compounds derived from 4-(chloromethyl)-2hydroxybenzaldehyde, J. Int. Pharm. Res., 46 (6), 133-138.

[10] Ahmed, W.M., Al-Saadawy, N.H., and Abowd, M.I., 2021, Synthesis and characterization of a new organoselenium and organotellurium compounds depending on 9-chloro-10-nitro-9,10dihydroanthracene, Ann. Romanian Soc. Cell Biol., 25 (4), 11035-11043.

[11] Kadhim, M.A., and Al-Saadawy, N.H., 2021, Synthesis and characterization for some new organoselenium compounds depending on 8hydroxyquinoline, Ann. Romanian Soc. Cell Biol., 25 (2), 2162-2172.

[12] El Adnani, Z., Mcharfi, M., Sfaira, M., Benzakour, M., Benjelloun, A., and Touhami, M.E., 2013, DFT theoretical study of 7-R-3methylquinoxalin-2(1H)thiones $\left(\mathrm{R}=\mathrm{H} ; \mathrm{CH}_{3} ; \mathrm{Cl}\right)$ as corrosion inhibitors in hydrochloric acid, Corros. Sci., 68, 223-230.

[13] Lu, Y., and Yamago, S., 2019, One-step synthesis of dendritic highly branched polystyrenes by organotellurium-mediated copolymerization of styrene and a dienyl telluride monomer, Angew. Chem. Int. Ed., 58 (12), 3992-3996.

[14] Bursch, M., Hansen, A., Pracht, P., Kohn, J.T., and Grimme, S., 2021, Theoretical study on conformational energies of transition metal complexes, Phys. Chem. Chem. Phys., 23 (1), 287-299.

[15] Salih, N.G., and Obayes, H.R., 2021, Theoretical study of $[\mathrm{N}]$-helicene structure $(\mathrm{N}=6,12,18,24,30$, 36, 42, 48, 54) using DFT, Solid State Technol., 64 (2), 3909-3919. 
[16] Gusakova, J., Wang, X., Shiau, L.L., Krivosheeva, A., Shaposhnikov, V., Borisenko, V., Gusakov, V., and Tay, B.K., 2017, Electronic properties of bulk and monolayer TMDs: Theoretical study within DFT framework (GVJ-2e method), Phys. Status Solidi A, 214 (12), 1700218.

[17] Asadi, N., Ramezanzadeh, M., Bahlakeh, G., and Ramezanzadeh, B., 2020, Theoretical MD/DFT computer explorations and surface-electrochemical investigations of the zinc/iron metal cations interactions with highly active molecules from Lemon balm extract toward the steel corrosion retardation in saline solution, J. Mol. Liq., 310, 113220.

[18] Shaw, R.A., 2020, The completeness properties of Gaussian-type orbitals in quantum chemistry, Int. J. Quantum Chem., 120 (17), e26264.

[19] McClain, J., Sun, Q., Chan, G.K.L., and Berkelbach, T.C., 2017, Gaussian-based coupled-cluster theory for the ground-state and band structure of solids, J. Chem. Theory Comput., 13 (3), 1209-1218.

[20] Pereira, F., Xiao, K., Latino, D.A.R.S., Wu, C., Zhang, Q., and Aires-de-Sousa, J., 2017, Machine learning methods to predict density functional theory B3LYP energies of HOMO and LUMO orbitals, J. Chem. Inf. Model., 57 (1), 11-21.

[21] Larock, R., 1985, Organomercury Compounds in Organic Synthesis, Springer-Verlag, New York.

[22] Al-Saadawy, N.H., Alyassin, F.F., and Faraj, H.R., 2016, Preparation and characterization of some new complexes of Schiff bases derived from benzoin and glycine, Global J. Pure Appl. Chem. Res., 4 (1), 13-20.

[23] Al-Rubaie, A.Z., Al-Salim, N.I., and Al-Jadaan, S.A.N., 1993, Synthesis and characterization of new organotellurium compounds containing an orthoamino group, J. Organomet. Chem., 443 (1), 67-70.

[24] Silverstein, R.M., Webster, F.X., and Kiemle, D.J., 2005, Spectrometric Identification of Organic
Chemistry Compounds, $7^{\text {th }}$ Ed., John Wiley \& Sons, New York, USA.

[25] Shriner, R.I., and Hermann, C.K., 2004, Spectroscopic Techniques for Organic Chemistry, John Wiley \& Sons, New York, USA.

[26] Ajeel, F.N., Khudhair, A.M., and Mohammed, A.A., 2015 , Density functional theory investigation of the physical properties of dicyano pyridazine molecules, Int. J. Sci. Res., 4 (1), 2334-2339.

[27] Ajeel, F.N., 2017, Analytical insight into the effect of electric field on molecular properties of homonuclear diatomic molecules, Curr. Smart Mater., 2 (2), 153-161.

[28] Alwan, A.S., Ajeel, S.K., and Jabbar, M.L., 2019, Theoretical study for Coronene and Coronene-Al, $\mathrm{B}, \mathrm{C}, \mathrm{Ga}$, In and Coronene-O interactions by using Density Functional theory, Univ. Thi-Qar J., 14 (4), 1-14.

[29] Oftadeh, M., Naseh, S., and Hamadanian, M., 2011, Electronic properties and dipole polarizability of thiophene and thiophenol derivatives via density functional theory, Comput. Theor. Chem., 966 (1-3), 20-25.

[30] Hanoon, F.H., Jabbar, M.L., and Alwan, A.S., 2017, Effect of thickness on the fractal optical modulator for $\mathrm{MgF}_{2}, \mathrm{LiF}, \mathrm{Al}_{2} \mathrm{O}_{3}$ materials by testing modulation transfer function (MTF), J. Coll. Educ. Pure Sci., 7 (4), 168-182.

[31] Hamd, E.K., Alwan, A.S., and Irthiea, I.K., 2018, Study the effect of welding heat input on the microstructure, hardness, and impact toughness of AISI 1015 steel, Al-Khwarizmi Eng. J., 14, 118-127.

[32] Alwan, A.S., 2020, Density functional theory investigation of $\left(\mathrm{C}_{4} \mathrm{H}_{2} \mathrm{~N}_{2}\right)_{3}$ nanocluster and $\left(\mathrm{C}_{4} \mathrm{H}_{2} \mathrm{~N}_{2}\right)_{3}-\mathrm{P}, \mathrm{Al}, \mathrm{As}, \mathrm{B}, \mathrm{C}$ and In nanoclusters, AIP Conf. Proc., 2292, 030013. 